DOI: 10.2478/v10141-009-0032-y

\title{
Models of Organisation of Youth Elite Sports Training System in Europe
}

\author{
Jolanta Żyśko, Monika Piątkowska
}

Josef Pilsudski University of Physical Education in Warsaw, Poland

ABSTRACT

The European Commission is aware of the professionalisation of sports and the requirements of profitableness that unavoidably induct risks for European young high-level athletes and takes care of their protection and of the quality of their training. Thus, the European Commission decided to realise a study on training of sportsmen/women in the 27 Member States of the European Union in order to be able to lead political or legal actions which would contribute to the promotion and development of high quality training.

The aim of the project was to identify ways of improving the legal and political framework for preserving and developing high-quality training for top-level sportspersons, particularly young sportspersons, in Europe. The study of the training of elite young sportsmen and sportswomen in Europe was conducted in all 27 Members States of UE in 2007. The research process was based on two main sources: legal and sports questionnaire.

This paper presents main models of organisation of youth elite sports training system. On the basis of the results of the study two main factors which have strong impact on the organisation of the training of young athletes were indicated: i) funding and supervision; ii) management of the training centres.

The organisation of sports in the different countries has a direct impact on the organisation of the training of young athletes. On the basis of obtained data 7 main models for the operation of training centres in all $27 \mathrm{UE}$ countries depending on two axes: funding and management. There is no unified system of supervision of the funds as it depends on the national regulations. Therefore, the grade and methods of this control from public institutions is different in $27 \mathrm{UE}$ member countries. In Poland we may observe a model based on public funding and a mix between sports clubs and national associations to operate the training centres.

KEYWORDS $\quad$ youth elite sport, organisation

In recent years sport has become more and more commercialised and the number of professional and semiprofessional athletes has grown significantly. To be successful today, athletes are obligated, from young age, to dedicate their time and energy almost executively to training and competition, often at the expense of education. There has been a tendency to focus on short-term goals 
in the pursuit of starting success which means that the question of life after sport has been overlooked. As a result, many athletes reach the end of their professional sports careers only to find themselves without the necessary academic or other vocational qualifications to gain employment in other sectors. In the present European Union member states an increasing impact of transnational factors on policy developed by their governments in various fields of social life may be observed. Emerging global and European structures, as well as the policy established by them, clearly affect national management systems in diverse fields of the state's operations. The intensification of transnational pressure frequently hinders or even replaces state policies in various fields of its activity (Henry 2005). Yet simultaneously the nature and specific character of the European Union favours reverse actions, i.e. enhancing national identity and even the impact of national policy in particular countries of united Europe on the policy and functioning of European community structures. This is due to the fact that the European integration process means not merely some sort of unification or introduction of solutions imposed by European structures. Europeanisation tends to foster local development and autonomy of member states that create the contemporary Europe.

As far as the policy regarding the training of young athletes is concerned, three levels may be observed in the model: European policy, national policy and organizational strategies. Although the European Union is aware of the significance of sport, it must be ascertained that there is no formal legal basis for the EU's direct commitment to sport. The Treaty of Amsterdam (1997) amending the Treaty on the European Union was the first European treaty which mentioned sport. The EU has not had any direct competency for this sector since the Protocol Annexed to the Treaty on European Union either.

Nevertheless, the European Commission has recognised the relevance of sport in the EU and is dealing increasingly with the issue of how sport in Europe can be organized in future. Therefore, the European Model of Sport has been launched. It is a democratic model that serves to ensure sport remains open to everyone. As a practical matter, the European Model of Sport appears as a pyramid structure, with clubs forming the base of the pyramid, offering maximum scope for local participation and promoting the idea of "sport for all". At the next level there are the regional associations and leagues, followed by the national federations, organising national championships and acting as regulatory bodies for all matters concerning their sport at national level. The top of the pyramid is constituted by the European federations, usually based on a structure of one member per national association.

Simultaneously with the European Model of Sport, there are national policies which regulate the training of young athletes. At the national level, in the European dimension different models and different policies of sport can be recognised. According to Camy at al. (2004) we can distinguish 4 models of sport governance: bureaucratic, entrepreneurial, social and missionary. The policy and logic of these models differs a lot from one to each other. The policy of training of young athletes is also different. The role of the state between Member States varied in relation to the education and sport. Henry at al. (2004) distinguished four models in terms of this:

» Direct state regulation of sport in the education sector is characterised by governments defining and requiring a desired outcome. This approach is usually accompanied by a strong institutional structure and strategic plan for sport, with a Government Ministry for Sport or relevant Federal or regional Dobies in states with a regional structure. It often includes such measures as state funded centres of excellence and/or the provision of strategically based facilities, together with national programmes of athlete development.

» Semi-regulation of sport in the education sector is characterised by governments facilitating a desired outcome and is usually accompanied by a more devolved policy development and 
decision-making structure for sport. In addition, there is often significant activity by nongovernmental organisations or quasi nongovernmental organisations, together with an active commercial sports sector providing facilities and services, including sports education and training centres. Regulation of the sector is less rigid than in the first category, with negotiation between stakeholders preferred as a method of policy development.

» Minimal regulation of sport in the education sector is characterised by a free market approach, with little regulation beyond basic health and safety, child protection and qualification verification measures.

» Non state intervention

Table 1 provides an overview of the nature of regulation of sport in the education sector in European countries.

Table 1: Member State intervention in sport and education

\begin{tabular}{ll}
\hline State intervention & Member states \\
\hline Maximum & Austria, Belgium, Denmark, France, Germany, Netherlands, Poland, \\
Semi-regulation & Estonia, Finland, Greece, Lithuania, Luxemburg, Spain, Sweden, UK \\
Minimal & Cyprus, Czech Republic, Hungary, Italy, Ireland, Latvia, Portugal, Slovenia \\
Non & Malta \\
\hline
\end{tabular}

Source: Education of young sportspersons - Lot 1. Final report. European Commission, DG Education and Culture, 2004

Not only was the important role of sport in the European society recognised, but so was the significance of protecting young talented athletes. This has been noticeable in the numerous documents ratified by the European Commission. Namely, it was acknowledged in December 2000 in the European Council's Declaration on the specific characteristics of sport and its social function in Europe, of which account should be taken in implementing common policies (the "Nice Declaration"):

"Training policies for young sportsmen and -women are the life blood of sport, national teams and top-level involvement in sport and must be encouraged. Sports federations, where appropriate in tandem with the public authorities, are justified in taking the action needed to preserve the training capacity of clubs affiliated to them and to ensure the quality of such training, with due regard for national and Community legislation and practices."

(Declaration on the specific ... 2000, p. 2)

A major milestone was reached in 2007 when the European Commission adopted a White Paper on Sport. This is the Commission's first comprehensive initiative on the subject of sport and it serves to provide it with guidance on sports-related measures in the years ahead. It contains numerous proposals for involving sport, i.e.:
"Investment in and promotion of training of young talented sportsmen and sportswomen in proper conditions is crucial for a sustainable development of sport at all levels. The Commission stresses that training systems for talented young sportsmen and sportswomen should be open to all and must not lead to discrimination between EU citizens based on nationality."

(White Paper on Sport 2007, p. 6)

In the consolidated versions of the Treaty on the European Union and the Treaty on the Functioning of the European Union (2008) the sport issues are broadly discussed. The Lisbon Treaty amends areas 
where the Union shall have competence to carry out actions to support, coordinate or supplement the actions of the member states. Among these it is proposed to include education, vocational training, youth and sport along with, for example, tourism, culture and health. In this document one may find:

"The Union shall contribute to the promotion of European sporting issues, while taking account of the specific nature of sport, its structures based on voluntary activity and its social and educational function."

(Consolidated versions... Article165, p.157)

It also emphasizes that:

"Union action shall be aimed at: (...) developing the European dimension in sport, by promoting fairness and openness in sporting competitions and cooperation between bodies responsible for sports, and by protecting the physical and moral integrity of sportsmen and sportswomen, especially the youngest sportsmen and sportswomen."

(Consolidated versions... Article165, p.157-158)

All the above-mentioned documents put strong emphasis on the protection of youth elite sportspersons. The European Council underlines the benefits of sport for young people and urges the need for special heed to be paid, in particular by sporting organisations.

The European Commission is aware of the professionalisation of sports and the requirements of profitableness that unavoidably induce risks for European young high-level athletes and it is concerned for their protection and the quality of their training. Thus, the European Commission has decided to implement a study on training sportsmen/women in the 27 Member States of the European Union in order be able to lead political or legal actions which would contribute to the promotion and development of high quality training.

The aim of the project was to identify ways of improving the legal and political framework for preserving and developing high-quality training for top-level sportspersons, particularly young sportspersons, in Europe. Therefore, it was important to:

Describe the current situation regarding the training of top-level sportspersons in Europe;

Identify different approaches to the training of top-level sportspersons in Europe;

Identify examples of best practice in certain training systems;

Evaluate the training needs of top-level sportspersons and, where appropriate, methods to improve their training.

The study of the training of elite young sportsmen and sportswomen in Europe was conducted in all 27 Members States of UE in 2007 (table 2). In Poland it was carried out by R. Pasternak and P. Turowicz (Deloitte Ltd. - legal experts) and by J. Żyśko and M. Piątkowska (Josef Pilsudski University of Physical Education in Warsaw - sports experts).

The research process was based on two main sources: i) legal questionnaires dealing with institutional, legal and political aspects, education and training of young athletes, health and protection of young athletes; ii) sports questionnaire: general organisation of sports in relation to the training of young talents fulfilled by local sports experts; organisation of the training of young athletes for each of the 5 selected sports per country fulfilled by the national associations directly or indirectly after an indepth interview with our local sports experts; organisation of some best practices in terms of training centres, to be fulfilled by the selected training centres.

The study was conducted on five sports per country. The three following sports: athletics, basketball and football were chosen in each country, in order to allow comprehensive comparison both by sports 
and country. This paper will show the results from the three disciplines. The selection of the two additional sports per country was required to address the following needs: identify best practices and ensure a good representativeness of the different types of sports at the European level. Table 2 presents the researched disciplines of sport in all 27 members of the European Union.

Table 2. Sport disciplines analysed in all $27 \mathrm{EU}$ countries

\begin{tabular}{|c|c|c|c|c|c|c|c|c|c|c|c|c|c|c|c|c|c|c|c|c|c|c|c|c|}
\hline & है & 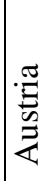 & 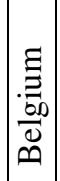 & 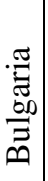 & 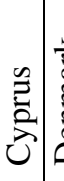 & 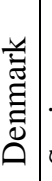 & : & 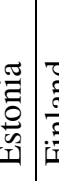 & 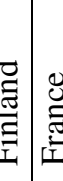 & 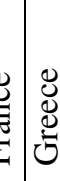 & 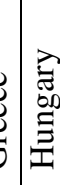 & 胥 & 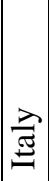 & 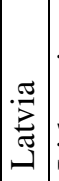 & ב & 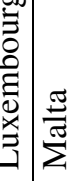 & 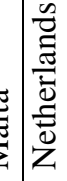 & $\mid \begin{array}{l} \\
\vec{\Xi} \\
\frac{\tilde{J}}{0} \\
2\end{array}$ & 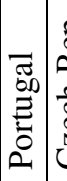 & 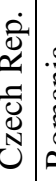 & & $4=\frac{. \pi}{\frac{\pi}{\sigma}}$ & $\begin{array}{l}\frac{\pi}{\pi} \\
\frac{0}{0} \\
\frac{0}{\omega}\end{array}$ & 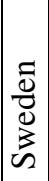 \\
\hline Athletics & & & & & & & & & & & & & & & & & & & & & & & & \\
\hline Football & & & & & & & & & & & & & & & & & & & & & & & & \\
\hline Basketball & & & & & & & & & & & & & & & & & & & & & & & & \\
\hline Cycling & & & & & & & & & & & & & & & & & & & & & & & & \\
\hline Fencing & & & & & & & & & & & & & & & & & & & & & & & & \\
\hline Gymnastics & & & & & & & & & & & & & & & & & & & & & & & & \\
\hline Handball & & & & & & & & & & & & & & & & & & & & & & & & \\
\hline Swimming & & & & & & & & & & & & & & & & & & & & & & & & \\
\hline Tennis & & & & & & & & & & & & & & & & & & & & & & & & \\
\hline Golf & & & & & & & & & & & & & & & & & & & & & & & & \\
\hline Ice hockey & & & & & & & & & & & & & & & & & & & & & & & & \\
\hline Judo & & & & & & & & & & & & & & & & & & & & & & & & \\
\hline Rugby & & & & & & & & & & & & & & & & & & & & & & & & \\
\hline Alpine ski & & & & & & & & & & & & & & & & & & & & & & & & \\
\hline $\begin{array}{l}\text { Cross } \\
\text { country ski }\end{array}$ & & & & & & & & & & & & & & & & & & & & & & & & \\
\hline
\end{tabular}

$\square$ Sports analysed in the study

Source: The study of the training of elite young sportsmen and sportswomen in Europe, EC, 2007

In Poland the study was carried out for athletics in the Polish Athletic Fedaration and MKS Polonia (youth athletics club), for basketball in the Polish Basketball Federation and OSSM Warsaw (youth basketball training centre) and for football in the Polish Football Association and Masovian Centre of Sport Training (Mazowiecki Ośrodek Szkolenia Sportowego OSSM) as for football, Polish Swimming Federation, Polish Fencing Federation, multisport athletic centre - COS in Spała. The interviews were conducted with the persons responsible for the training and supervision of the organisation.

This paper focuses on presenting the main models of organization of youth elite sports training system. On the basis of the results of the study two main factors which have a strong impact on the organisation of the training of young athletes were indicated: i) funding and supervision (whether public or private); and ii) management of the training centres (who is responsible for operating the centre?) (European Commission 2007).

In the area of funding and supervision of the training centre the research shows two different approaches in the $27 \mathrm{EU}$ member countries depending on whether this concerns centres in professional or Olympic sports. In professional sports the training centres are mainly financed from private funding (i.e. TV rights, ticketing, sponsoring). However, local governments and national associations are also responsible for funding and supervision. As for Olympic sports, the funding mostly comes from public 
resources - states and local governments - and is distributed by national associations. There is no unified system of supervision of the funds as this depends on the national regulations. Therefore, the grade and methods of this control from public institutions is different in the $27 \mathrm{EU}$ member countries. Apart from the direct relationship in funding of the training centres (State $\rightarrow$ National associations $\rightarrow$ Training centres) the indirect relationship in supervision and funding may be indicated through various types of organisations such as GSO or Semi GSO (i.e. UK Sport, CONI) and NGSO (i.e. National Olympic Committees).

The second important factor which was pointed out concerned responsible agents for the management of the training centres. These included, namely, national associations, sports clubs and other private bodies. The national associations may either manage their own training centres (for part or whole of the development programme) oronly be involved in the talent identification system or the management of youth national teams. Sports clubs are always part of the system but their role depends not only on the sports discipline but on the country as well. There are some sports clubs which run the best training centres in the country and are responsible for the whole training process, while others focus on some categories of ages.

On the basis of two main factors - funding (horizontal axis) and responsible agents for the management (vertical axis) - the research team identified seven main models for the operation of training centres in all $27 \mathrm{EU}$ countries which are shown in figure 1.

Figure 1. Representation of the main models for the operation of training centres

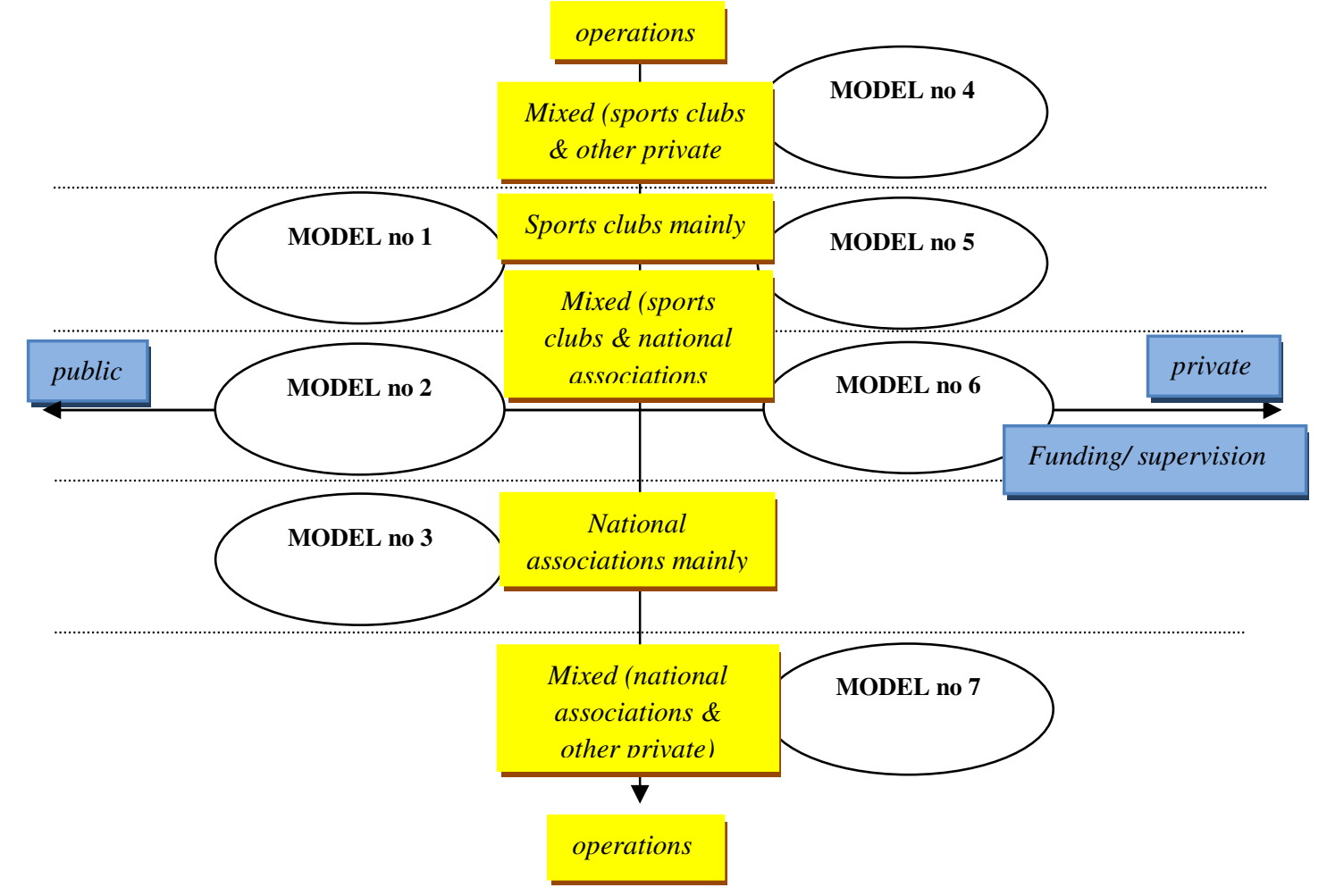

Source: The study of the training of elite young sportsmen and sportswomen in Europe, EC, 2007

The first model assumes public funding and considers sports clubs as main operators of training centres. This model is regarded as not the most common one. The second model is also based on public funding but sees a mix between sports clubs and national associations as the responsible bodies for operating the training. This model is found to be main model as far as Olympic sports are concerned. Model no 3 considers public funding and national associations as the main operators of 
training centres. This is the other main model for Olympic sports. All the other models (nos 4, 5, 6, 7) benefit from private funding. Model no 4 sees a mix between sports clubs and private bodies to operate the training centres. This model exists in some individual professional sports. Model no 5 assumes sports clubs to be the main operators of training centres. This model is very common in professional team sports. Model no 6 is based on a mix between sports clubs and national associations operating the training centres. As well as the previously mentioned model, this one also exists in some cases for professional team sports. The last model (no 7) considers a mix between national associations and private bodies as the main operators of the training centres. It should be noticed that this is not a common model, but it can occur in some individual professional sports.

On the basis of the obtained data, not all models are perceptible in the researched countries. The organisation of sports in the different countries has a direct impact on the organisation of the training of young athletes. The results including three sporting disciplines (A-athletics, B-basketball, F-football) in all 27 member states have been introduced on the matrix assuming two axes: funding and supervision and management of the training centres (Figure 2).

Figure 2. Representation of the models for the operation of training centres in researched countries.

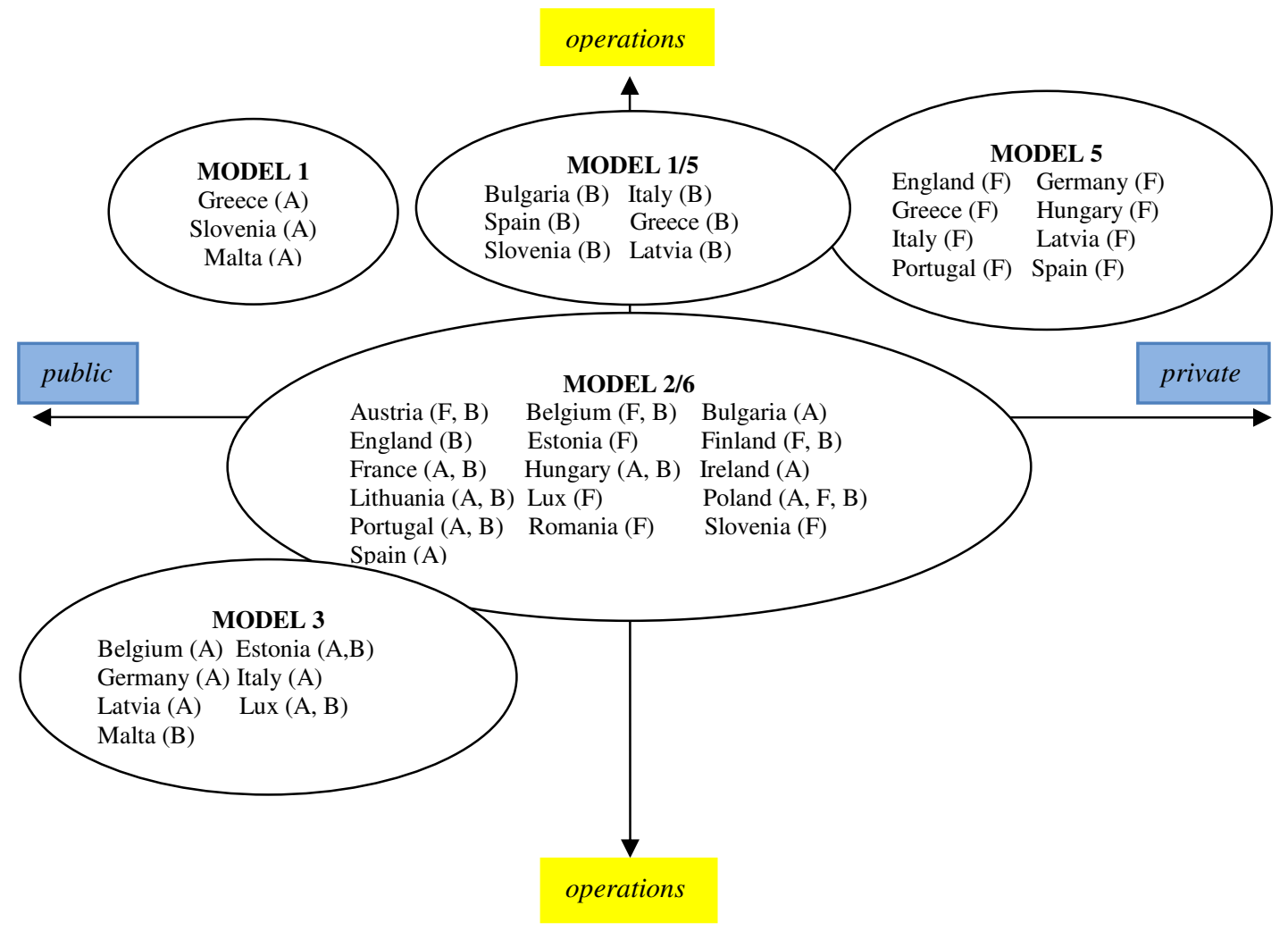

Sources: Own study on the basis of the study into the training of elite young sportsmen and sportswomen in Europe, EC, 2007

In a limited number of countries, most of the work is done at the clubs' level, most of the times with the indirect support of the national associations - model no 1 can be found in Greece, Slovenia and Malta (athletics) as far as athletics is concerned.

In some smaller countries, the national association is the main player and gathers the best young talents from a rather young age in a sole national training centre [model no 3: Estonia, Latvia, Luxemburg, Malta (basketball)] while in some larger countries, the national association also gathers the best talents but in several training centres (model no 3: Germany, Italy, Belgium). 
In other countries, the national association is mainly dealing with national teams, organizing training camps and the training of coaches, but does not directly train players all year long. Model no 5 may be observed in England, Germany, Greece, Hungary, Italy, Latvia, Portugal and Spain, mainly as far as football is concerned.

There are also mixed models which exist in some researched countries. Model no 1/5 is visible in a limited number of countries. It exists mostly where the basketball economy seems to be strong, and therefore where clubs are the main actors. In the case of basketball this model may be found in Spain, Greece, Slovenia, Latvia, Bulgaria, and Italy.

As it is shown in Chart 3, a dominant position is occupied by model no 2/6. In the majority of countries (Austria, Belgium, Bulgaria, England, Estonia, Finland. France, Hungary, Ireland, Lithuania, Luxembourg, Poland, Portugal, Romania, Slovenia, Spain ${ }^{1}$ ), a mixed role is played by the clubs and the national associations. Clubs train young talents until they reach the required level and age and afterwards get into national or regional training centres (which does not happen too soon since i.e. athletics is a late-maturity sport). The national associations play a significant role in the training of players, gathering on a permanent basis some of the best players in the country, either at a specific age or over the full training path. In some countries, especially the smaller ones, funding does not only come from private sources (i.e. Luxemburg).

To conclude, there is no unified system of supervision of the funds as it depends on the national regulations. Therefore, the grade and methods of this control from public institutions is different in the $27 \mathrm{EU}$ member countries. In Poland we may observe a model based on public funding and a mix between sports clubs and national associations operating the training centres.

Most of the countries present a mix between the clubs and the national associations as fas as the main operators of the training centres are concerned.

In some countries, national associations play the main role in a number of sports: Estonia (through Audentes School of Sport), Belgium (for individual sports), Luxemburg (for all sports as the local market is not big enough for clubs to be able to reach the required level).

In a few countries (i.e. Spain, Slovenia, Greece), the national association leaves or helps the clubs to do the training on their own in a few sports. Latvia is found as a very specific country where, depending on the sports, either the national associations or the clubs will play the main role.

It should also be noticed that even though the project was carried out in all 27 member states of the European Union, not all researched countries may be found on the model of organisation of youth elite training centres. This may arise from insufficient data or simply a lack of data coming from various organisations: clubs, training centres and national associations located in different countries.

\section{REFERENCES}

Combining sports and education: Support for athletes in the EU Member States. Working Paper. European Parliament, Directorate - General for Research, Education and Culture Series. EDUC 114 EN, Luxembourg, 2003.

Consolidated versions of the Treaty on European Union and the Treaty on the functioning of the European Union (2008) 6655/1/08 REV 1 Council Of The European Union. Brussels, 30 April 2008.

\footnotetext{
1 It must be noted that in many cases different models may be found in one country depending on the sporting discipline. For instance Greece represents three models of organisation of youth elite training centres: in athletics - model no 1 , in basketball - model no $1 / 5$, in football - model no $1 / 5$.
} 
Declaration on the specific characteristics of sport and its social function in Europe, of which account should be taken in implementing common policies (2000) no 13948/00 DGJ.

European Commission (2004). Education in elite sport in Europe, System Portraits. Summary. DG Education and Culture.

European Commission (2004). Education of young sportspersons - Lot 1. Final report. DG Education and Culture.

European Commission (2007). Study on the training of young sportsmen and sportswomen in Europe. Ineum Consulting - Taj.

European Commission (2000). Directorate-General X Information, Communication, Culture, Audiovisual Media. Audiovisual policy, culture and sport. The European Model of Sport.

European Commission (2007). White Paper on Sport. SEC(2007) 932, 934, 935, 936.

Henry, I. (2005). Sport, the role of the European Union and the decline of the nation state? In B. Houlihan (Ed.), Sport and Society. London, Thousand Oaks, New Delhi: SAGE Publications. 